\title{
Application of Square-wave Pulse Heat Method to Thermal Properties Measurement of $\mathrm{CaO}-\mathrm{SiO}_{2}-\mathrm{Al}_{2} \mathrm{O}_{3}$ System Fluxes
}

\author{
Koki NISHIOKA, Takayuki MAEDA and Masakata SHIMIZU \\ Department of Materials Science and Engineering, Faculty of Engineering, Kyushu University, 774, Motooka, Nishi-ku, \\ Fukuoka 819-0395 Japan.
}

(Received on September 2, 2005; accepted on November 11, 2005)

\begin{abstract}
The square-wave pulse heat method was improved to measure thermal properties of vitreous samples by considering radiation heat transfer between the front and back faces of the samples, and the measurement accuracy of the method was examined.

Thermal properties of $\mathrm{CaO}-\mathrm{SiO}_{2}-\mathrm{Al}_{2} \mathrm{O}_{3}$ samples were measured by the method. Thermal diffusivities of the crystalline $40 \mathrm{CaO}-40 \mathrm{SiO}_{2}-20 \mathrm{Al}_{2} \mathrm{O}_{3}(\mathrm{~mol} \%)$ sample are about 1.5-2.5 times larger than those of the vitreous sample. Specific heat of the crystalline and vitreous samples shows almost the same temperature dependency, except the highest measurement temperature due to crystallization of glass.

Finally, we investigated the reason that the thermal conductivity values measured by the improved square-wave pulse heat method differ from those by the line source method. As a result, crystallization of glass during the measurements would cause the difference of the temperature dependencies of the values measured by the two methods.
\end{abstract}

KEY WORDS: square-wave pulse heat method; thermal diffusivity; specific heat; thermal conductivity; slags.

\section{Introduction}

Thermal properties of molten slags and fluxes are very important factors affecting the efficiency in metallurgical operations and the values are also essential to mathematical modeling for various phenomena involved in iron and steelmaking processes. For examples, mould powders used in the continuous casting of steels exist as both liquid and sold states between the steel and the mould, and control the heat transfer. The heat transfer between the steel and the mould largely affects the surface quality of the steel.

Major components of the mould powders are $\mathrm{CaO}, \mathrm{SiO}_{2}$, and $\mathrm{Al}_{2} \mathrm{O}_{3}$. Figure 1 summarizes a part of previous studies on thermal properties (thermal diffusivity, thermal conductivity and heat capacity) measurements ${ }^{1-8)}$ of $\mathrm{CaO}-\mathrm{SiO}_{2}-$ $\mathrm{Al}_{2} \mathrm{O}_{3}$ system slags. For example, thermal properties of fused and crystalline $\mathrm{SiO}_{2}$ were measured by Wray et al. ${ }^{1)}$ and others. ${ }^{2,3)}$ Regarding the $\mathrm{CaO}-\mathrm{SiO}_{2}$ binary system, only the thermal conductivity of $57 \mathrm{CaO}-43 \mathrm{SiO}_{2}(\mathrm{~mol} \%)$ slags were measured by several researchers. ${ }^{2,4)}$ Not enough numbers of measurements were conducted on $\mathrm{Al}_{2} \mathrm{O}_{3}$ containing slags.

The square-wave pulse heat method $^{9-11)}$ can measure thermal diffusivity, specific heat and thermal conductivity of crystalline samples which have very small values of thermal diffusivity such as oxides and heterogeneously structured composite materials simultaneously with a high degree of accuracy because a halogen lamp having several hundred watts output power is usually used as energy source instead of laser pulse in the laser pulse method. However, radiation heat transfer between the front and back faces of the samples during the measurements should be considered when the thermal properties of vitreous samples are measured by the square-wave pulse heat method.

Therefore, in this work, we improved the square-wave pulse heat method to be able to measure the thermal properties of vitreous samples. Then we measured thermal diffusivity, heat capacity and thermal conductivity of $\mathrm{CaO}-\mathrm{SiO}_{2}$ and $\mathrm{CaO}-\mathrm{SiO}_{2}-\mathrm{Al}_{2} \mathrm{O}_{3}$ system slags. Finally, we investigated the difference of the thermal conductivity values, $45 \mathrm{CaO}-$

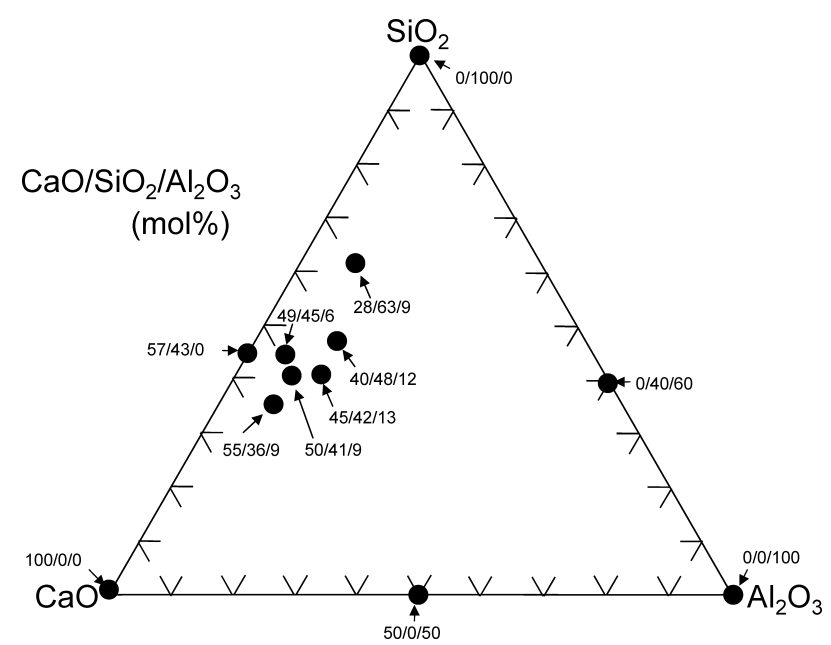

Fig. 1. Compositions of samples whose thermal properties were measured. 


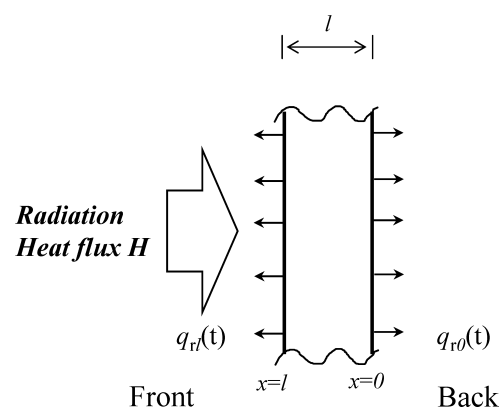

Fig. 2. Boundary conditions for the square-wave pulse heat method.

$42 \mathrm{SiO}_{2}-13 \mathrm{Al}_{2} \mathrm{O}_{3}(\mathrm{~mol} \%)$ as an example, measured by the improved square-wave pulse heat method and line source method. ${ }^{8)}$

\section{Experimental Method}

\subsection{Principle of the Square-wave Pulse Heat Method}

Consider an infinite plate of $l(\mathrm{~m})$ in thickness, which is in thermal equilibrium with its surrounding atmosphere. A square wave pulse $\left(H\left(\mathrm{~W} / \mathrm{m}^{2}\right)\right.$ in heat flux and $\delta(\mathrm{s})$ in time width) is directed onto the front face of the plate (Fig. 2). When the temperature rise from the initial temperature is $u$ $(\mathrm{K})$, governing equation and boundary conditions are given by the following equations..$^{9,11)}$

$$
\begin{gathered}
\frac{\partial u}{\partial t}=\alpha \frac{\partial^{2} u}{\partial x^{2}} \quad(0<x<l) \\
k\left[\frac{\partial u}{\partial x}\right]_{x=0}=q_{x 0}(t) \ldots . \\
k\left[\frac{\partial u}{\partial x}\right]_{x=l}=H-q_{x l}(t) \ldots \\
H= \begin{cases}0 & (t<0, t>\delta) \\
H & (0 \leq t \leq \delta)\end{cases}
\end{gathered}
$$

where it is assumed that thermal properties of samples such as thermal conductivity $k(\mathrm{~W} / \mathrm{m} \cdot \mathrm{K})$, specific heat $C_{\mathrm{p}}$ $(\mathrm{kJ} / \mathrm{kg} \cdot \mathrm{K})$, thermal diffusivity $\alpha\left(\mathrm{m}^{2} / \mathrm{s}\right)$ are independent of temperature and position. $q_{x 0}(t)$ and $q_{x l}(t)$ in Eqs. (2) and (3) are heat losses by radiation at the front and back faces $\left(\mathrm{W} / \mathrm{m}^{2}\right)$, respectively. When the initial temperature $T_{0} \gg$ the temperature rise $u$, the heat loss at the front face $q_{x l}(t)$ can be linearized as $q_{x l}(t)=4 \varepsilon_{x} \sigma T_{0}{ }^{3} u$. When $F_{0}=\alpha t / l^{2}$ and $F_{\delta}=\alpha \delta / l^{2}, u$ at the back face can be calculated from Eqs. (5) and (6).

$$
\begin{aligned}
u= & \frac{1}{a+b} \\
& -2 \sum_{n=0}^{\infty} \frac{1}{P_{n} \sin P_{n}\left(1+a-2 \frac{b}{a}+\frac{P_{n}^{2}}{a}+\frac{b}{P_{n}^{2}}+\frac{b^{2}}{a P_{n}^{2}}\right)} \\
& \times \exp \left(-F_{0} P_{n}^{2}\right) ; \quad(0 \leq t<\delta)
\end{aligned}
$$

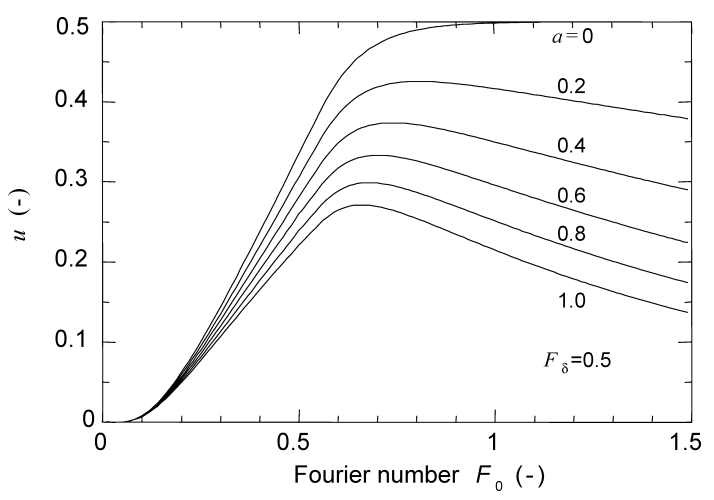

Fig. 3. Relationship between temperature response curve and radiation parameter.

$$
u=2 \sum_{n=0}^{\infty} \frac{\left\{\exp \left(P_{n}^{2} F_{\delta}\right)-1\right\} \exp \left(-P_{n}^{2} F_{0}\right)}{P_{n} \sin P_{n}\left(1+a-2 \frac{b}{a}+\frac{P_{n}^{2}}{a}+\frac{b}{P_{n}^{2}}+\frac{b^{2}}{a P_{n}^{2}}\right)}
$$

$$
(\delta \leq t)
$$

where $P_{n}$ is the $n$th solution satisfying $\cot P=P / a-b /(a P)$, $a$ and $b$ are heat radiation parameters. When the emissivities of the front and back faces are the same

$$
a=\frac{8 \varepsilon_{0} \sigma u_{0}^{3} l}{k}, \quad b=\left(\frac{4 \varepsilon_{0} \sigma u_{0}^{3} l}{k}\right)^{2}, \quad b=\frac{a^{2}}{4}
$$

Therefore, $u$ is a function of $F_{0}, F_{\delta}$ and $a$. Figure 3 shows temperature response-curves calculated from Eqs. (5) and (6), when $F_{\delta}=0.5, a=0.0-1.0$. In Fig. 3, $a=0.0$ means no heat loss from the faces by radiation.

The Marquardt method ${ }^{12)}$ has been used to calculate thermal diffusivities of samples by fitting Eqs. (5) and (6) to the monitored temperature response-curves at the back face during measurements. Fitting parameters for the Marquardt method used in this work are thermal diffusivity $\alpha$ and heat radiation parameter $a$.

Specific heats of samples are calculated from Eq. (8).

$$
C_{\mathrm{p}}=\frac{H \delta}{\rho l u_{\mathrm{cnst}}}
$$

where $\rho\left(\mathrm{kg} / \mathrm{m}^{3}\right)$ is the density and $u_{\mathrm{cnst}}(\mathrm{K})$ is the maximum temperature rise without heat loss by radiation. It is impossible to measure $u_{\text {cnst }}$ directly because of heat loss from the front and back faces by radiation, especially, at high temperatures. Therefore, in this work, at first $\alpha$, and $a$ were obtained by fitting Eqs. (5) and (6) to the monitored temperature response-curve at the back face. Secondly, a temperature response-curve at the back face without heat loss from the faces was calculated by substituting $\alpha$ obtained from the parameter fitting and $a=0.0$ into Eqs. (5) and (6). At last, the maximum temperature rise without heat loss by radiation $\left(u_{\text {cnst }}\right)$ was calculated from the temperature rise at $F_{0} \geq 1.0$. Since thermal diffusivities and specific heats of samples were calculated by the procedure mentioned above, thermal conductivities of the samples were calculated from Eq. (9). 


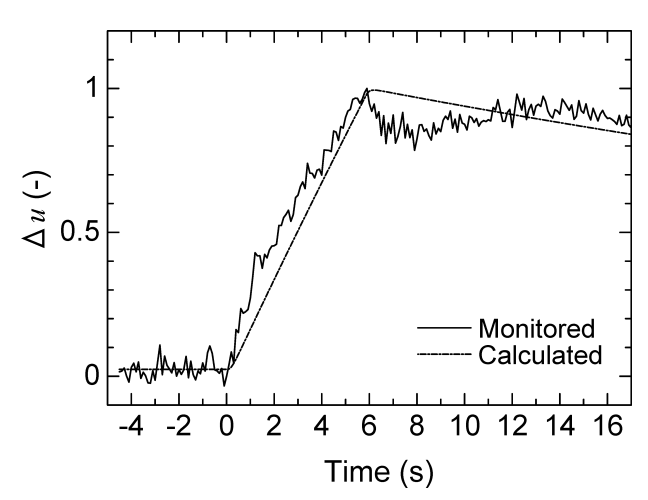

Fig. 4. Example of monitored and numerically calculated temperature response-curves in the square-wave pulse heat method.

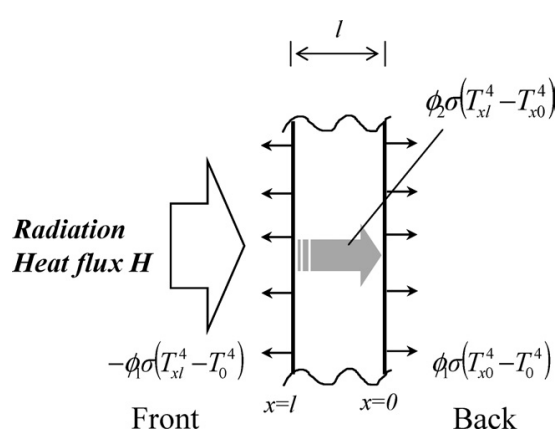

Fig. 5. Boundary conditions for the improved square-wave pulse heat method.

$$
k=\alpha \rho C_{\mathrm{p}}
$$

An example of monitored temperature response-curves of a vitreous sample and numerically calculated temperature response-curves by the square-wave pulse heat method is shown in Fig. 4. The numerically calculated temperature response-curve does not agree with the monitored one because radiation heat transfer between the front and back faces of the vitreous sample is not considered in the squarewave pulse heat method. Therefore, radiation heat transfer between the front and back faces of samples should be considered correctly to measure thermal properties of transparent materials by the square-wave pulse heat method.

\subsection{Improved Square-wave Pulse Heat Method}

Consider a transparent infinite plate of $l(\mathrm{~m})$ in thickness, which is in thermal equilibrium with its surrounding. A square wave pulse is directed onto the front face of the plate (Fig. 5). When the temperature of the sample is $T(\mathrm{~K})$ and the initial temperature is $T_{0}(\mathrm{~K})$, governing equation and boundary conditions are given by the following equations.

$$
\begin{array}{r}
\frac{\partial T}{\partial t}=\alpha \frac{\partial^{2} T}{\partial x^{2}} \quad(0<x<l) \ldots \ldots \ldots \ldots \ldots . . . . . . . . \\
k\left[\frac{\partial T}{\partial x}\right]_{x=0}+\phi_{2}\left(T_{x l}^{4}-T_{x 0}^{4}\right)=\phi_{1}\left(T_{x 0}^{4}-T_{0}^{4}\right) \ldots \ldots . \\
k\left[\frac{\partial T}{\partial x}\right]_{x=l}-\phi_{2}\left(T_{x l}^{4}-T_{x 0}^{4}\right)=H-\phi_{1}\left(T_{x l}^{4}-T_{0}^{4}\right) \ldots .
\end{array}
$$

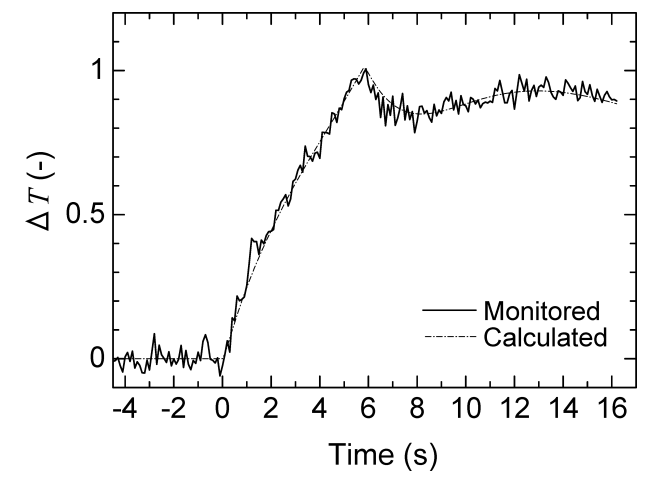

Fig. 6. Example of monitored and numerically calculated temperature response-curves in the improved square-wave pulse heat method.

$$
H= \begin{cases}0 & (t<0, t>\delta) \\ H & (0 \leq t \leq \delta)\end{cases}
$$

where $\phi_{1}(-)$ is the geometrical factor of the both faces to the surrounding, $\phi_{2}$ is the geometrical factor between the front and back faces, $T_{x l}(\mathrm{~K})$ is the temperature of the front face, $T_{x 0}$ is the temperature of the back face.

Difference equations were derived from the equations based on the finite difference method. The difference equations were solved by the Crank-Nicholson method on equally spaced grids of the one-dimensional coordinate system. The number of the grids was 40 . Time increment was $1.0 \times 10^{-3} \mathrm{~s}$. The Marquardt method has been also used to calculate thermal diffusivity and specific heat of samples. Fitting parameters are thermal diffusivity $\alpha$ and specific heat $C_{\mathrm{p}}$ and geometrical factors $\phi_{1}$ and $\phi_{2} . \alpha$ and $C_{\mathrm{p}}$ were accepted when the geometrical factors satisfied geometrical conditions. An example of monitored temperature response-curves of the vitreous sample and numerically calculated ones by the improved square-wave pulse heat method is shown in Fig. 6. The numerically calculated temperature response-curve reproduces properly the complicated monitored one. Thermal conductivity of the sample $k$ was calculated by multiplying thermal diffusivity $\alpha$, density $\rho$ and specific heat $C_{\mathrm{p}}$ as described in Eq. (9).

\subsection{Experimental Equipment}

A schematic diagram of the experimental equipment to measure thermal properties of samples is shown in Fig. 7. The front and back faces of the sample were coated with a black body paste to fix surface emissivity. Fine ceramic fiber was filled between the side face of the sample and the sample holder to prevent radiation heat transfer between the sample and the holder. Pt-Pt-13\%Rh thermo-couples of $0.1 \mathrm{~mm}$ in diameter were attached at the back face of the sample to monitor back face temperatures during measurements. There is a shutter equipped with a photo-sensor between a halogen lamp and a silica glass window to measure irradiation time of a square-wave pulse. The temperature was recorded with a personal computer through a digital volt meter every $0.1 \mathrm{~s}$.

\subsection{Experimental Procedure}

At first, the sample holder was placed on a designated position in the chamber. The pressure of the chamber was 
reduced with the rotary and diffusion pumps less than $1.0 \times 10^{-3} \mathrm{~Pa}$ to prevent convection heat transfer. Temperature of the sample was maintained at a certain measurement temperature. A square-wave pulse of 2-10 s was irradiated onto the front face of the sample after the sample had attained thermal equilibrium. The back face temperature of the sample was recorded during the experiment. Measurements were conducted in the temperature range $293-1150 \mathrm{~K}$ at intervals of $100 \mathrm{~K}$. Heat fluxes onto the samples, which are required to calculate specific heat of samples, were measured in advance as a function of measurement temperature with as received $\mathrm{MgO}$ samples whose specific heat and density were known. Thermal diffusivity, specific heat and thermal conductivity of crystalline samples were measured by the square-wave pulse heat method, and those of vitreous samples were measured by the improved square-wave pulse heat method to eliminate the effect of radiation heat transfer between the front and back faces of the samples.

\section{Sample Preparation}

Fused $\mathrm{SiO}_{2}(10.0 \mathrm{~mm}$ in diameter, $10.0 \mathrm{~mm}$ in height,

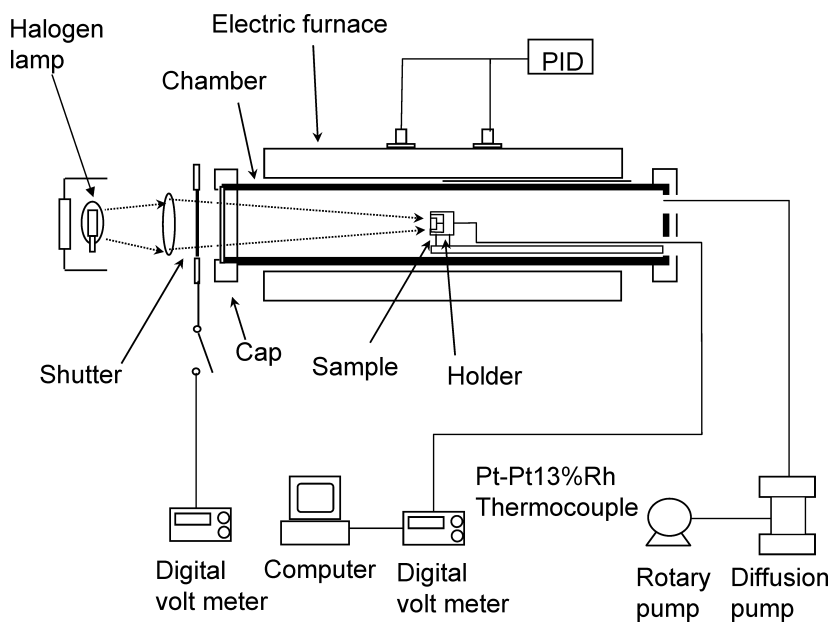

Fig. 7. Schematic diagram of experimental equipment.
99.9 mass \% in purity) was employed for the validation of the improved square-wave pulse heat method.

Samples of $x \mathrm{CaO}-(100-x) \mathrm{SiO}_{2}(\mathrm{~mol} \%)$ were prepared from reagent grade $\mathrm{CaCO}_{3}$ and $\mathrm{SiO}_{2}$ powders. Weighed mixtures of $\mathrm{CaCO}_{3}$ and $\mathrm{SiO}_{2}$ were melted in platinum crucibles in air for $1800 \mathrm{~s}$ at $1923 \mathrm{~K}$ and poured into a watercooled copper mold. The bulk samples were crushed into powder. The powder was pressed at $250 \mathrm{MPa}$ by a hydraulic press, crystallized and sintered in air for $24 \mathrm{~h}$ at $1673 \mathrm{~K}$. Properties of the samples are shown in Table 1.

Samples of $x \mathrm{CaO}-x \mathrm{SiO}_{2}-y \mathrm{Al}_{2} \mathrm{O}_{3}(\mathrm{~mol} \%)$, where $y=0-20$ and $2 x+y=100$, and $45 \mathrm{CaO}-42 \mathrm{SiO}_{2}-13 \mathrm{Al}_{2} \mathrm{O}_{3}(\mathrm{~mol} \%)$ were prepared from reagent grade $\mathrm{CaCO}_{3}, \mathrm{SiO}_{2}, \mathrm{Al}_{2} \mathrm{O}_{3}$ powders. Weighed mixtures of $\mathrm{CaCO}_{3}, \mathrm{SiO}_{2}$, and $\mathrm{Al}_{2} \mathrm{O}_{3}$ were placed in platinum crucibles and melted in air for $1800 \mathrm{~s}$ at 1923 $\mathrm{K}$. Bulk glasses were prepared by pouring the melts into the water-cooled copper mold. Then the bulk samples were annealed in air for $10800 \mathrm{~s}$ at $973 \mathrm{~K}$ to remove residual stress. The bulk samples were cut and machined into a disc of $10.0 \mathrm{~mm}$ in diameter and $4.5 \mathrm{~mm}$ in height to make vitreous samples. Properties of the samples are shown in Table 2. The bulk glass samples mentioned above were crushed into powder, pressed at $125 \mathrm{MPa}$ by the hydraulic press, crystallized and sintered in air for $24 \mathrm{~h}$ at $1173 \mathrm{~K}$. Properties of the samples are shown in Table 3. The phases in the vitreous and crystalline samples were determined by X-ray diffraction analysis. No crystalline was detected in the vitreous samples. Differential thermal analysis (DTA) of the vitreous samples was performed at cooling and heating rates of $0.167 \mathrm{~K} / \mathrm{s}$.

Table 1. Properties of $\mathrm{CaO}-\mathrm{SiO}_{2}$ samples.

\begin{tabular}{cccccc}
\hline No. & $\begin{array}{c}\mathrm{CaO}: \mathrm{SiO}_{2} \\
(\mathrm{~mol} \%)\end{array}$ & Mass $(\mathrm{g})$ & Diam.(mm) & Height(mm) & Porosity(\%) \\
\hline 1 & $35: 65$ & 1.509 & 9.75 & 10.6 & 30 \\
2 & $40: 60$ & 1.509 & 9.50 & 10.7 & 24 \\
3 & $45: 55$ & 1.339 & 9.45 & 7.75 & 19 \\
4 & $50: 50$ & 1.489 & 9.70 & 8.80 & 20 \\
5 & $55: 45$ & 1.497 & 9.10 & 8.15 & 4 \\
\hline
\end{tabular}

Table 2. Properties of $\mathrm{CaO}-\mathrm{SiO}_{2}-\mathrm{Al}_{2} \mathrm{O}_{3}$ vitreous samples.

\begin{tabular}{cccccccc}
\hline No. & $\begin{array}{c}\mathrm{CaO} \\
(\mathrm{mol} \%)\end{array}$ & $\begin{array}{c}\mathrm{SiO}_{2} \\
(\mathrm{~mol} \%)\end{array}$ & $\begin{array}{c}\mathrm{Al}_{2} \mathrm{O}_{3} \\
(\mathrm{~mol} \%)\end{array}$ & Mass $(\mathrm{g})$ & Diam. $(\mathrm{mm})$ & Height(mm) & $\begin{array}{c}\text { Apparent density } \\
\left(10^{3} \mathrm{~kg} / \mathrm{m}^{3}\right)\end{array}$ \\
\hline 6 & 50 & 50 & 0 & 0.91 & 9.80 & 4.40 & 2.74 \\
7 & 47.5 & 47.5 & 5 & 0.96 & 9.70 & 4.40 & 2.81 \\
8 & 44.5 & 44.5 & 11 & 0.96 & 10.0 & 4.50 & 2.71 \\
9 & 40 & 40 & 20 & 0.93 & 9.85 & 4.55 & 2.68 \\
10 & 45 & 42 & 13 & 0.94 & 9.85 & 4.55 & 2.71 \\
\hline
\end{tabular}

Table 3. Properties of $\mathrm{CaO}-\mathrm{SiO}_{2}-\mathrm{Al}_{2} \mathrm{O}_{3}$ crystalline samples.

\begin{tabular}{cccccccc}
\hline No. & $\begin{array}{c}\mathrm{CaO} \\
(\mathrm{mol} \%)\end{array}$ & $\begin{array}{c}\mathrm{SiO}_{2} \\
(\mathrm{~mol} \%)\end{array}$ & $\begin{array}{c}\mathrm{Al}_{2} \mathrm{O}_{3} \\
(\mathrm{~mol} \%)\end{array}$ & Mass $(\mathrm{g})$ & Diam. $(\mathrm{mm})$ & Height(mm) & $\begin{array}{c}\text { Apparent density } \\
\left(10^{3} \mathrm{~kg} / \mathrm{m}^{3}\right)\end{array}$ \\
\hline 11 & 50 & 50 & 0 & 1.01 & 9.70 & 5.90 & 2.32 \\
12 & 47.5 & 47.5 & 5 & 0.99 & 8.75 & 5.90 & 2.81 \\
13 & 44.5 & 44.5 & 11 & 1.00 & 8.85 & 6.70 & 2.43 \\
14 & 40 & 40 & 20 & 1.02 & 8.85 & 6.00 & 2.76 \\
15 & 45 & 42 & 13 & 1.03 & 8.90 & 6.00 & 2.76 \\
\hline
\end{tabular}



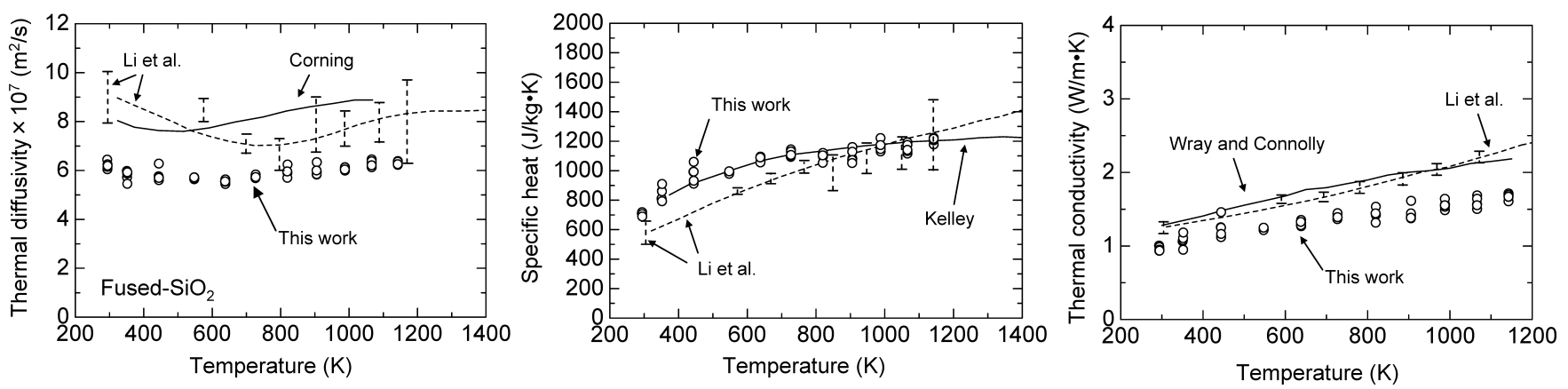

Fig. 8. Comparison of thermal properties measured in this work with those by other methods.
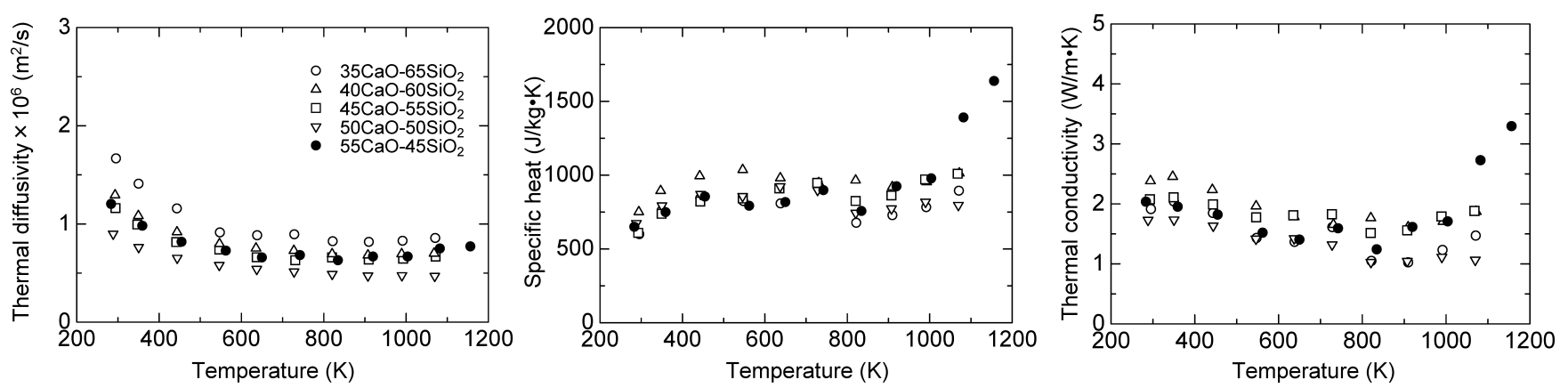

Fig. 9. Thermal properties of crystalline $\mathrm{CaO}-\mathrm{SiO}_{2}$ samples as functions of temperature.

\section{Results and Discussion}

\subsection{Validation of the Improved Square-wave Pulse Heat Method}

Figure 8 shows thermal diffusivity, specific heat, and thermal conductivity of fused $\mathrm{SiO}_{2}$ measured by the improved square-wave pulse heat method. The thermal diffusivities in this work decrease with increasing measurement temperature from room temperature to $700 \mathrm{~K}$, and increase progressively above $700 \mathrm{~K}$. Values reported by Li et al. ${ }^{13)}$ and Corning ${ }^{14)}$ show similar temperature dependencies. The specific heats increase from $723 \mathrm{~J} / \mathrm{kg} \cdot \mathrm{K}$ at $294 \mathrm{~K}$ to 862 $\mathrm{J} / \mathrm{kg} \cdot \mathrm{K}$ at $1142 \mathrm{~K}$. Kelley's values ${ }^{15)}$ agree well with the values obtained in this work. Regarding the thermal conductivities, Wray and Connolly's values ${ }^{1)}$ are slightly higher (by 8 to $23 \%$ ) than the values in this work. This is probably due to the thermal boundary layer of the cooling water around $\mathrm{SiO}_{2}$ rod in their experimental apparatus.

Considering the facts that the numerically calculated back face temperature reproduces the monitored one with minute accuracy, that the variations of values measured by Li et al. ${ }^{13)}$ shown in Fig. 8 are relatively large, and that specific heats and thermal conductivities obtained in this work almost agree with ones measured by the other methods, we concluded that the thermal properties of vitreous samples can be measured by the improved square-wave pulse heat method.

\section{2. $\mathrm{CaO}-\mathrm{SiO}_{2}$ System}

Figure 9 shows thermal diffusivity, specific heat and thermal conductivity of crystalline $\mathrm{CaO}-\mathrm{SiO}_{2}$ samples measured by the square-wave pulse heat method. The effect of pores was removed by using Kunii's equation. ${ }^{16)}$ Regarding the thermal diffusivity and thermal conductivity, an increase in $\mathrm{SiO}_{2}$ content causes increases in the thermal diffu- sivity and conductivity values, except $55 \mathrm{CaO}-45 \mathrm{SiO}_{2}$. Thermal diffusivity and thermal conductivity of $55 \mathrm{CaO}-$ $45 \mathrm{SiO}_{2}$ are larger than those of $50 \mathrm{CaO}-50 \mathrm{SiO}_{2}$. This is probably due to the effect of $\mathrm{Ca}_{3} \mathrm{Si}_{2} \mathrm{O}_{7}\left(3 \mathrm{CaO} \cdot 2 \mathrm{SiO}_{2}\right)$ formation. There is no obvious relation between the specific heats and compositions.

\section{3. $\mathrm{CaO}-\mathrm{SiO}_{2}-\mathrm{Al}_{2} \mathrm{O}_{3}$ System}

\subsubsection{Vitreous Samples}

Figure 10 shows thermal diffusivity, specific heat and thermal conductivity of vitreous $\mathrm{CaO}-\mathrm{SiO}_{2}-\mathrm{Al}_{2} \mathrm{O}_{3}$ samples measured by the improved square-wave pulse heat method. The temperature dependencies of the thermal diffusivity and specific heat are insensitive to $\mathrm{Al}_{2} \mathrm{O}_{3}$ concentration at temperatures below $1000 \mathrm{~K}$. The thermal diffusivity of samples, however, are scattered and suddenly decreased around $1000-1200 \mathrm{~K}$. For example, the glass transition temperature $\left(T_{\mathrm{g}}\right)$ for $40 \mathrm{CaO}-40 \mathrm{SiO}_{2}-20 \mathrm{Al}_{2} \mathrm{O}_{3}(\mathrm{~mol} \%)$ sample obtained by DTA was $1153 \mathrm{~K}$. When the measurement temperature slightly exceeded $T_{\mathrm{g}}$, glass structure partially changed due to the temperature rise caused by irradiation of the square-wave pulse to the sample. Therefore, measured thermal diffusivities decrease apparently because glass transition is an endothermic reaction. The specific heats of samples increase gradually as increasing the measurement temperatures up to $500 \mathrm{~K}$, and settle down around $500 \mathrm{~K}$. The specific heats of samples are scattered above $1000 \mathrm{~K}$ due to transition of glass as in the case of the thermal diffusivities. The thermal conductivities of samples were obtained by multiplying densities, thermal diffusivities and specific heats of samples as described above; thus, the thermal conductivities of the samples were insensitive to $\mathrm{Al}_{2} \mathrm{O}_{3}$ concentration, and the values are scattered above $1000 \mathrm{~K}$ as in the cases of the thermal diffusivities and specific heats. 

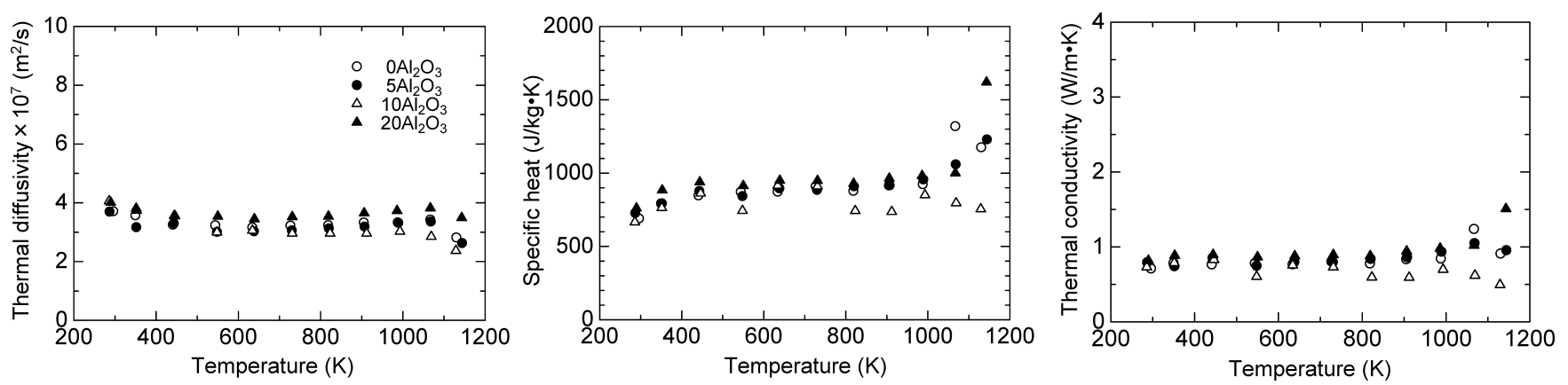

Fig. 10. Thermal properties of vitreous $\mathrm{CaO}-\mathrm{SiO}_{2}-\mathrm{Al}_{2} \mathrm{O}_{3}$ samples as functions of temperature.
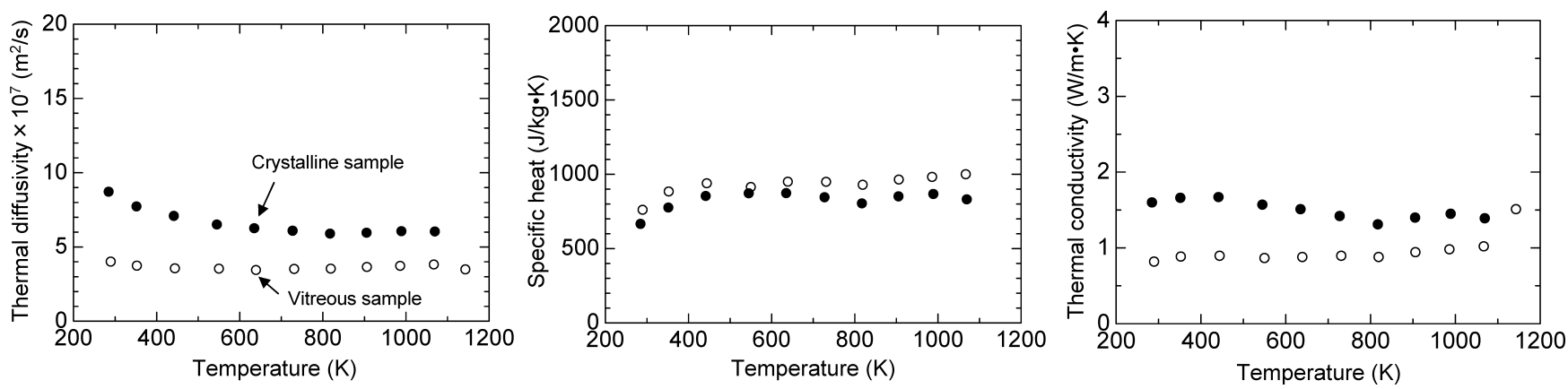

Fig. 11. Effect of crystallization on thermal properties of $40 \mathrm{CaO}-40 \mathrm{SiO}_{2}-20 \mathrm{Al}_{2} \mathrm{O}_{3}$.

\subsubsection{Effect of Crystallization}

Figure 11 shows the effect of crystallization on thermal diffusivity, specific heat and thermal conductivity of $40 \mathrm{CaO}-40 \mathrm{SiO}_{2}-20 \mathrm{Al}_{2} \mathrm{O}_{3}$ samples. The thermal diffusivities of the crystalline sample are about 1.5-2.5 times larger than those of the vitreous sample. The thermal diffusivities of the crystalline sample decrease as increasing measurement temperature. In contrast, the thermal diffusivities of the vitreous sample are nearly constant. The specific heats of the crystalline and vitreous samples show almost the same temperature dependencies, except the highest measurement temperature due to crystallization of glass. The thermal conductivities of the crystalline sample are about 1.5-2.5 times larger than those of the vitreous sample as in the case of the thermal diffusivities because the specific heats of the crystalline and vitreous samples are almost the same values. Regarding the thermal conductivities, values of crystalline samples decrease as increasing measurement temperature due to a decrease of mean free path of phonon.

\subsubsection{Comparison with Line Source Method}

Figure 12 shows thermal conductivities of $45 \mathrm{CaO}-$ $42 \mathrm{SiO}_{2}-13 \mathrm{Al}_{2} \mathrm{O}_{3}(\mathrm{~mol} \%)$ samples measured with the line source method by Susa et al. ${ }^{8)}$ and in this work. The thermal conductivities of the vitreous sample measured in this work are about $20-45 \%$ lower than those measured by the line source method. The thermal conductivities of the crystalline sample measured in this work are almost equal to or slightly larger than those measured by the line source method below $750 \mathrm{~K}$. Considering the facts that glass transition temperature of the sample is $1153 \mathrm{~K}$ and that thermal conductivities of the vitreous and crystalline samples in this work show almost the same values at $1000 \mathrm{~K}$, glass probably crystallized progressively as increasing measurement temperature in their work as shown by the broken line in

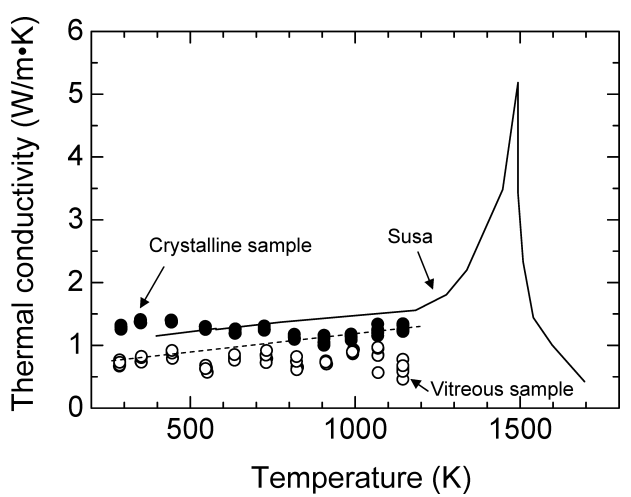

Fig. 12. Comparison between thermal conductivities for $45 \mathrm{CaO}-42 \mathrm{SiO}_{2}-13 \mathrm{Al}_{2} \mathrm{O}_{3}$ measured by the line source method and the improved square-wave pulse heat method.

Fig. 12. The reason that thermal conductivities measured by the improved square-wave pulse heat method are about $15-30 \%$ lower than those by the line source method is still under examination.

\section{Conclusions}

The square-wave pulse heat method was improved to measure thermal properties of vitreous samples. Thermal properties of crystalline $\mathrm{CaO}-\mathrm{SiO}_{2}$ and $\mathrm{CaO}-\mathrm{SiO}_{2}-\mathrm{Al}_{2} \mathrm{O}_{3}$ samples were measured by the square-wave pulse heat method; those of vitreous $\mathrm{CaO}-\mathrm{SiO}_{2}-\mathrm{Al}_{2} \mathrm{O}_{3}$ samples were measured by the improved square-wave pulse heat method. The following results were obtained.

(1) The improved square-wave pulse heat method is applicable to the measurement of vitreous samples. The thermal diffusivities, thermal conductivities and specific heats of fused- $\mathrm{SiO}_{2}$ measured by the improved square-wave pulse 
heat method were in good agreement with those measured by other methods.

(2) There is no obvious effect of $\mathrm{Al}_{2} \mathrm{O}_{3}$ concentration on the thermal properties of vitreous $x \mathrm{CaO}-x \mathrm{SiO}_{2}-y \mathrm{Al}_{2} \mathrm{O}_{3}$ samples $(y=0-20 \mathrm{~mol} \%)$.

(3) The thermal diffusivities of the crystalline $40 \mathrm{CaO}-$ $40 \mathrm{SiO}_{2}-20 \mathrm{Al}_{2} \mathrm{O}_{3}(\mathrm{~mol} \%)$ sample are about $1.5-2.5$ times larger than those of the vitreous sample. The specific heats of crystalline and vitreous samples show almost the same temperature dependencies, except the highest measurement temperature due to crystallization of glass.

(4) The thermal conductivities of the $45 \mathrm{CaO}-42 \mathrm{SiO}_{2}-$ $13 \mathrm{Al}_{2} \mathrm{O}_{3}(\mathrm{~mol} \%)$ sample measured by the improved squarewave pulse heat method are about $15-30 \%$ lower than those by the line source method. The reason is still under examination.

\section{REFERENCES}

1) K. L. Wary and T. J. Connolly: J. Appl. Phys., 30 (1959), 1702.

2) K. Nagata and K. S. Goto: Proc. of 2nd Int. Symp. on Metallurgical Slags and Fluxes, The Metallurgical Society of AIME, Warrendale,
PA, (1984), 875 .

3) C. F. Lucks, H. W. Deem and W. D. Wood: J. Am. Ceram. Soc., 39 (1960), 313.

4) T. Sakuraya, T. Emi, H. Ohta and Y. Waseda: J. Jpn. Inst. Met., 46 (1982), 1131

5) M. Kishimoto, M. Maeda, K. Mori and Y. Kawai: Proc. of 2nd Int. Symp. on Metallurgical Slags and Fluxes, The Metallurgical Society of AIME, Warrendale, PA, (1984), 891.

6) K. Ogino, A. Nishiwaki and K. Yamamoto: Tetsu-to-Hagané, 65 (1979), S683.

7) K. Nagata, M. Susa and K. S. Goto: Tetsu-to-Hagané, 69 (1983), 1417.

8) M. Susa: Master's Thesis, Tokyo Institute of Technology, (1981).

9) K. Kobayashi and T. Kobayashi: Trans. Jpn. Soc. Mech. Eng. B, 46B (1980), 1318.

10) K. Kobayashi and T. Takano: Trans. Jpn. Soc. Mech. Eng. B, 48B (1982), 2062.

11) K. Nishioka and T. Murayama and Y. Ono: Tetsu-to-Hagané, 83 (1997), 707.

12) D. W. Marquardt: J. Soc. Ind. Appl. Math., 11 (1963), 431.

13) F. Li, M. Susa and K. Nagata: J. Jpn. Inst. Met., 55 (1991), 194.

14) Corning: Bull. Low Expansion Mater, (1969), 12.

15) K. K. Kelley: US Bur. Mines, (1949)

16) T. Kunii: Netsuteki-Tanni-Sousa (In Japanese), Maruzen, Tokyo, (1976), 123. 